\title{
Climate Change: New Trends and Projections
}

\author{
M. H. Saier Jr. • J. T. Trevors
}

Published online: 31 January 2007

(C) Springer Science + Business Media B.V. 2007

The two most dangerous problems facing humankind are (1) the excessive and expanding human population, and (2) anthropogenic greenhouse gas production. Of course the latter problem results from the former one, not the other way around, so a reduction in the number of humans on Earth will be required to solve any of our serious environmental problems. Hopefully, this will result from a decrease in the fertility rate rather than an increase in the death rate. But how serious is the problem of global warming, and what are the most recent trends and developments?

Production of $\mathrm{CO}_{2}$ and other types of mangenerated pollution has been increasing dramatically in recent years. At the International Conference on Global Environmental Change in Beijing, November 2006, scientists reported that despite efforts to reduce carbon emissions, they have actually increased. Specifically, the report documented that in the period between 2000 and 2005 as compared with the period between 1990 and 1995, $\mathrm{CO}_{2}$ emissions from fossil

\footnotetext{
M. H. Saier Jr. ( $\square)$

Biological Sciences, University of California at San Diego, La Jolla, CA 92093-0116, USA

e-mail: msaier@ucsd.edu

J. T. Trevors

Department of Environmental Biology,

University of Guelph,

Guelph, ON, Canada, N1G 2W1

e-mail: jtrevors@uoguelph.ca
}

fuel consumption increased by 400 PERCENT! The data were published by the Global Carbon Project (http://www.globalcarbonproject.org), a component of the Earth System Science Partnership. Dr Mike Raupach, Chair of the Global Carbon Project, noted that "The findings indicate that recent efforts to reduce emissions have had virtually no impact on emissions growth, and that effective caps are urgently needed."

Anthropogenic carbon dioxide release over the last 5 years are close to one of the more pessimistic emissions scenarios from the Intergovernmental Panel on Climate Change (IPCC) called "A1B." This scenario assumes that at least $50 \%$ of energy produced over the next century will come from fossil fuel consumption. The recent increases were attributed to the tremendous enhancement in fossil fuel consumption in China and India as well as the actions of the U.S. and Australia in disregarding and even undermining the efforts of the Kyoto Accord. Worse, assuming "business as usual," the data suggest that at least an 8-fold increase in $\mathrm{CO}_{2}$ emissions will occur over the next 10 years. None of the recent projections had anticipated such a rapid rise in anthropogenic $\mathrm{CO}_{2}$ production.

Most frighteningly, due to the phenomenon of environmental inertia, if and when anthropogenic emissions $d o$ begin to decrease, atmospheric $\mathrm{CO}_{2}$ will continue to rise for at least a century. Moreover, global temperatures will continue to increase for two or more centuries, locking the world into continuing 
climate change. Effective management of Earth system inertia depends on early and consistent actions.

Another startling study was published by the UN food and farming agency and the Rome-based Food and Agriculture Organization (FAO) on November 29, 2006. This study concluded that the livestock industry contributes to the greenhouse effect, as measured in $\mathrm{CO}_{2}$ equivalents, as much or more than do cars. Meat production is also a major source of soil and water pollution. Livestock now accounts for $18 \%$ of manmade carbon emissions, driven by the surge in demand for meat and dairy products by the world's burgeoning populations. Global meat production is expected to more than double, from 230 million tons in 2001 to over 460 million tons in 2050. Similarly, U.N. projections indicate that milk output will soar from 550 million to about 1,100 million tons over the same period.

Surprisingly, livestock manure decomposition generates $65 \%$ of human-caused nitrous oxide, a gas that is 300 times more effective at trapping solar heat than carbon dioxide, and livestock ruminants account for $37 \%$ of all human-induced methane. Per molecule, methane is 24 times more warming than $\mathrm{CO}_{2}$. To make matters even worse, $64 \%$ of man-made ammonia, a big contributor to acid rain, results from meat production. For many reasons, therefore, livestock demands including the need for feed crops, contribute very significantly to biodiversity loss. This information should provide us all with incentive to eat less meat and switch to more vegetarian diets. We owe it to our children, the Earth and ourselves.

In a third study, published in the renowned journal, Science in November 2006, the state of the Earth's oceans was evaluated. It was concluded that if global warming, pollution and fishing around the world continue unabated, marine ecosystems will unravel, and there will be a "global collapse" of all marine species. This will occur sometime before 2050. In order to avert this disaster, it was concluded that we must act immediately to protect marine ecosystem diversity.

The marine life studied included all fish, shellfish and invertebrates that are consumed by people. The new analyses revealed that one-third of these species had their numbers reduced to less than $10 \%$ of values that existed just 50 years ago. Pollution, ocean acidity and warming, and habitat loss in addition to fishing were the primary causes.

A combination of short-term solutions were recommended in order to improve this situation. These include legislating against global warming and other forms of pollution, preventing overfishing while protecting bycatch, outlawing practices that destroy ocean ecosystems, and establishing large marine reserves. However, all of these efforts could prove ineffective if the human population continues to grow. The only ultimate solution is to decrease the global population of Homo sapiens. Such efforts involving universal availability of birth control and abortion services while encouraging lifestyles that do not involve procreation will require the cooperation of all nations in a massive international effort funded by the wealthy nations of the world.

The conclusions cited above were derived as a result of detailed studies conducted by several international groups. In spite of the severity of this situation, it seems likely that little or nothing will be done, given the greedy shortsightedness of our politicians and the general public. Concerning the urgency of this situation, environmental education is a must if we are to maintain a healthy planet which can sustain a diversity of higher life forms. And there is no time to lose. 